\title{
Impact of a reactive capacity production on the firm's operational management under carbon cap and trade system
}

\author{
Jinpyo Lee a $^{*}$
}

${ }^{a}$ College of Business Administration, Hongik University, Seoul, Republic of Korea

\begin{tabular}{l}
\hline C H R O N I C L E \\
\hline Article history: \\
Received November 5, 2018 \\
Accepted December 2018 \\
Available online \\
December 2018 \\
\hline Keywords: \\
Carbon cap and trading system \\
Reactive capacity production \\
Green management
\end{tabular}

\section{Introduction}

Nowadays, there has been increased public consensus that the firm's social responsibility is critical for both its own business and public area. Firm's social responsibility implies requires responsibility for its activities beyond its own economic interests. With this need to be socially and environmentally responsible, firms have faced significant pressure to address climate change, especially in carbon emissions related production in their business together with its own objective. To address the need to be socially and environmentally responsible, we consider a firm which makes a production decision under the carbon emission cap and trade system.

There are several studies addressing the production management considering the carbon emission. Letmathe and Balakrishnan (2005) introduced an optimal production planning subject to environment conditions. Hua et al. (2011) used Economic Ordering Quantity (EOQ) model for the optimal order quantity to analyze the impact of carbon trade, price, and cap on ordering planning, carbon emissions, and total cost on the firm's efficiency. Chen et al. (2013) used the EOQ model for firm's operational decision with carbon cap, carbon tax, carbon offset and carbon reward to suggest a condition for the

* Corresponding author

E-mail address: jinpyo.lee@,hongik.ac.kr (J. Lee)

C 2019 by the authors; licensee Growing Science, Canada doi: $10.5267 /$ j.uscm.2018.12.001 
possible reduction of carbon emissions by modifying ordering planning. Caro et al. (2013) modeled the multiple firms' efforts in a supply chain for the reduction of carbon emissions and showed that the overall emissions for each firm more than the total supply chain emissions are induced to make the optimal emission-reduction efforts. Cachon et al. (2014) developed a simple density model for a retailer's choice of the size, location, and number of stores by integrating a carbon emissions cost in the total cost. Granot et al. (2014) used a cooperative game to suggest a Shapley value rule inducing members in supply chain to make carbon emission reduction effort. Du et al. (2015) used the newsvendor model to address the impact of carbon emission cap-and-trade system on a simple supply chain, in which two-stage system with one emission-dependent manufacturer and one permit supplier was considered. Hovelaque and Bironneau (2015) proposed an EOQ model under carbon tax system. An and Lee (2018) considered a reactive capacity production model under carbon cap and trade system in which the carbon emission from the initial production chance is only constrained but not from the second production chance for carbon emission cap and trade.

As the firm's production decision methodology in this study, we consider a reactive capacity production strategy under the carbon cap and trade market. The firm with a reactive capacity production strategy has two chances to choose the production quantities while it also considers total carbon emission from two production chances subject to the carbon cap and the amount of carbon emission traded in the carbon trading market. This is more practical and complex than choosing a single chance for the production quantity without carbon cap and trade constraint since we need the carbon emission cap constraint including the carbon emission from the second production which is not realized when deciding the first production. To cope quickly with the consumer's changing taste, the reactive capacity production strategy has been widely used and it is one of the essential production strategies in the mass production industry. An and Lee (2018) developed three methods for allocating total carbon emissions to each firm using a Stackelberg game based on a Newsvendor model between non-cooperative firms.

As shown in the previous studies, there has not been any comprehensive model that simultaneously address multiple issues on the impact of the production strategy on the firm's efficiency under the carbon cap and trade system. To the best of our knowledge, there is no study for a model which considers the issues of the firm's reactive production strategy by considering the carbon emission from both the first and the second production under the carbon cap and trade system. So, this study is pretty much new so that we think that it would bridge the research gap in the production decision model under the carbon trading system.

The rest of this paper is organized as follows. Section 2 describes the model for the firm's production decisions both with and without a reactive capacity production strategy, establishes the model optimization for both cases and then provides some results from the given models. Section 3 provides an empirical results and is followed by the conclusion in section 4 .

\section{Production Decision Under Carbon Trading System}

We consider firm regulated with respect to carbon emissions by the policymaker who decides the carbon cap and carbon price in the carbon trading market. Given the carbon emission cap and carbon trading price regulated by the policymaker, the firm makes optimal production decisions. Here, we will evaluate the value of the reactive capacity production. Reactive capacity production is defined as a production capacity strategy associated with later production by which the initial production is to commit to some supply before demand is realized but then there is an option to produce additional supply after some demand is realized (Cachon \& Terwiesch, 2008). To evaluate the impact of the reactive capacity production on the firm's efficiency under the carbon cap and trading system, we need to consider two firms as follows:

1. The firm without the reactive capacity production strategy: This firm has only one chance to produce the product before the demand is realized. 
2. The firm with the reactive capacity production strategy: This firm has two chances to produce the product.

One of two chances is before the demand is realized and the other is after the demand is realized. Even though each firm has different strategy for the production, both firms are equally constrained by the carbon emission cap. So, if either firm's carbon emission is less than the carbon cap, it can sell its carbon surplus through carbon trading market. Otherwise, they can purchase the carbon emission permit through carbon trading market to fill the carbon deficit. We will show the production decision model for the firm without the reactive capacity production strategy in section 2.1 and then production decision model for the firm with the reactive capacity production strategy in section 2.2.

\subsection{Production Decision without Reactive Capacity Strategy}

In this section, we model the production decision for the firm without the reactive capacity production strategy. This implies that the firm has one chance to produce the product only before the demand is realized. First, the firm makes a production quantity decision $Q$ before the demand $D$ is realized. The probability density function (pdf) and cumulative distribution function (cdf) for demand $D$ are $f(\cdot)$ and $F(\cdot)$, respectively. After the demand $D$ is realized, we have the objective function with carbon emission constraint as follows;

$$
\begin{gathered}
-c Q+p \min [D, Q]+s[Q-D]^{+}+c_{e} x \\
\text { s.t. } e Q+x=A
\end{gathered}
$$

where $p$ is the product's selling price, $s$ is the salvage price, $c$ is the production price, $x$ is the amount of carbon the manufacturer can trade in the carbon trading market, $c_{e}$ is the carbon trading price per unit of emission, $e$ is the carbon emission per unit of product and $A$ is the carbon cap. The constraint $e Q+x=A$ can be explained as follows: The amount of traded carbon emissions $x$ can be either positive or negative. A negative amount implies that the firm's carbon emissions are larger than its carbon cap and the firm can purchase that amount of carbon permission through the carbon trading market at the price of $c_{e}$. A positive amount of traded carbon emissions implies that the firm's carbon emissions are less than its carbon cap and can be sold through the carbon market at $c_{e}$. Hence, the amount of the traded carbon emissions $x$ should be constrained to be equal to $(A-e Q)$. Since the firm has one chance to produce the product only before the demand is realized, it needs to optimize its expected profit function before the demand is realized as follows,

$$
\max _{Q \geq 0}-c Q+\int_{0}^{\infty}\left(p \min [D, Q]+s[Q-D]^{+}+c_{e}(A-e Q)\right) f(D) d D,
$$

where $[x]^{+}=\max [x, 0]$. Lemma 1 shows how the firm makes its optimal production quantity decision when there is only one production chance.

Lemma 1. The firm makes the optimal production decision as follows,

Proof.

$$
\text { Production decision }=F^{-1}\left(\frac{p-c-c_{e} e}{p-s}\right)
$$

The firm's expected profit function can be written as follows,

$$
\begin{aligned}
-c Q+\int_{0}^{\infty}(p & \left.\min [D, Q]+s[Q-D]^{+}+c_{e}(A-e Q)\right) f(D) d D \\
& =-c Q+c_{e}(A-e Q)+\int_{0}^{Q}(p D+s[Q-D]) f(D) d D+\int_{Q}^{\infty} p Q f(D) d D
\end{aligned}
$$


Using the first order optimal condition for the firm's expected profit function, we have

$$
\begin{aligned}
\frac{d}{d Q}\left[-c Q+c_{e}\right. & \left.(A-e Q)+\int_{0}^{Q}(p D+s[Q-D]) f(D) d D+\int_{Q}^{\infty} p Q f(D) d D\right] \\
& =-c-c_{e} e+p Q f(Q)+\int_{0}^{Q} s f(D) d D-p Q f(Q)+\int_{Q}^{\infty} p f(D) d D \\
& =-c-c_{e} e+s F(Q)+p(1-F(Q))=0 .
\end{aligned}
$$

Therefore, the firm's first production decision is as follows,

$$
Q=F^{-1}\left(\frac{p-c-c_{e} e}{p-s}\right)
$$

Q.E.D

As shown in Lemma 1, the firm's optimal production decision is a function of carbon price and the carbon emission per unit production. In Lemma 2, we show that the firm's optimal production decision has a monotone property with respect to carbon price and the carbon emission per unit production.

Lemma 2. The firm's production quantity decreases as the carbon price $c_{e}$ or the carbon emission per unit production $e$ increases.

Proof.

From Lemma 1, the firm's production quantity $Q$ is given by

$$
Q=F^{-1}\left(\frac{p-c-c_{e} e}{p-s}\right)
$$

and $F(\cdot)$ is non-decreasing function, $Q$ is decreasing as the carbon price $c_{e}$ or the carbon emission per unit production $e$ increases.

Q.E.D

\subsection{Production Decision with Reactive Capacity Strategy}

Now, we consider the situation where the firm has two production chances: (1) it makes the initial production decision $Q$ before the demand $D$ is realized (2) then it makes the second production decision $[D-Q]^{+}$after the demand $D$ is realized. Actually, the second decision is contingent on the first decision. So, considering the two possible production chances and carbon emission cap and trade constraint, the firm needs to make the initial production decision. After the demand $D$ is realized, the firm's profit function with carbon emission constraint is given as follows;

$$
\begin{gathered}
-c Q+p D+s[Q-D]^{+}-c^{\prime}[D-Q]^{+}+c_{e} x \\
\text { s.t. } \quad e Q+e[D-Q]^{+}+x=A
\end{gathered}
$$

where $c^{\prime}$ is the second production cost per unit product with the reactive capacity production $\left(c^{\prime}>c\right)$. Since $x=A-e Q-e[D-Q]^{+}$, the firm has the expected profit function which needs to be optimized over $Q$, as follows;

$$
\max _{Q \geq 0}-c Q+\int_{0}^{\infty}\left(p D+s[Q-D]^{+}-\left(c^{\prime}+c_{e} e\right)[D-Q]^{+}+c_{e}(A-e Q)\right) f(D) d D .
$$

Lemma 3 shows how the firm makes its optimal initial and second production quantity decision when there are two production chances by considering the higher second production cost. 
Lemma 3. The firm's first and second optimal production quantity decisions are given by

$1^{\text {st }}$ production quantity decision $=F^{-1}\left(\frac{c^{\prime}-c}{c^{\prime}+c_{e} e-s}\right)$

$2^{\text {nd }}$ production quantity decision $=\left[D-F^{-1}\left(\frac{c^{\prime}-c}{c^{\prime}+c_{e} e-s}\right)\right]^{+}$for each realized demand $D$

Proof.

The firm's expected profit function can be written as follows,

$$
\begin{gathered}
-c Q+\int_{0}^{\infty}\left(p D+s[Q-D]^{+}-\left(c^{\prime}+c_{e} e\right)[D-Q]^{+}+c_{e}(A-e Q)\right) f(D) d D \\
=-c Q+p E[D]+c_{e}(A-e Q)+\int_{0}^{Q} s[Q-D]^{+} f(D) d D \\
+\int_{Q}^{\infty}-\left(c^{\prime}+c_{e} e\right)[D-Q]^{+} f(D) d D
\end{gathered}
$$

Using the first order optimal condition for the firm's expected profit function, we have

$$
\begin{gathered}
\frac{d}{d Q}\left[-c Q+p E[D]+c_{e}(A-e Q)+\int_{0}^{Q} s[Q-D] f(D) d D+\int_{Q}^{\infty}-\left(c^{\prime}+c_{e} e\right)[D-Q] f(D) d D\right] \\
=-c-c_{e} e+\int_{0}^{Q} s f(D) d D+\int_{Q}^{\infty}\left(c^{\prime}+c_{e} e\right) f(D) d D \\
=-c-c_{e} e+s F(Q)+\left(c^{\prime}+c_{e} e\right)(1-F(Q))=0 .
\end{gathered}
$$

Therefore, the firm's first production decision is as follows,

$$
Q=F^{-1}\left(\frac{c^{\prime}-c}{c^{\prime}+c_{e} e-s}\right)
$$

and the firm's second production decision for each scenario $\omega$ is as follows,

$$
[D-Q]^{+}=\left[D-F^{-1}\left(\frac{c^{\prime}-c}{c^{\prime}+c_{e} e-s}\right)\right]^{+}
$$

Q.E.D

In Lemma 4, we can see that the firm's initial and second production decisions with reactive capacity production strategy have a monotone decreasing and non-decreasing property with respect to carbon price and the carbon emission per unit production, respectively.

Lemma 4. As the carbon price $c_{e}$ or the carbon emission per unit production $e$ increases,

1. The firm's initial production quantity decreases.

2. The firm's second production quantity increases almost surely.

Proof.

Since, from Lemma 3, the firm's first production quantity $Q$ is given by

$$
Q=F^{-1}\left(\frac{c^{\prime}-c}{c^{\prime}+c_{e} e-s}\right)
$$


and $F(\cdot)$ is non-decreasing function, $\frac{c^{\prime}-c}{c^{\prime}+c_{e} e-s}$ is decreasing as the carbon price $c_{e}$ or the carbon emission per unit production $e$ increases. Thus, $Q$ is decreasing as $c_{e}$ or $e$ increases and the first result holds. Now, the firm's second production decision for every scenario $\omega$ is given by

$$
[D-Q]^{+}=\left[D-F^{-1}\left(\frac{c^{\prime}-c}{c^{\prime}+c_{e} e-s}\right)\right]^{+},
$$

as $c_{e}$ or $e$ increases, $F^{-1}\left(\frac{c^{\prime}-c}{c^{\prime}+c_{e} e-s}\right)$ decreases so that the firm's second production decision for every scenario $\omega$ is increasing. Thus, the second result holds.

Since the firm with the reactive capacity production strategy has a second production chance after the demand is realized, intuitively it would produce less quantity of products than the firm without the reactive capacity production strategy. This intuition is explained in Proposition 1.

Proposition 1. The first production quantity $Q_{1}^{W O}$ without reactive capacity strategy is larger than the first production quantity $Q_{1}^{W}$ with reactive capacity strategy.

Proof. We need to compare the first production decision for each strategy;

$$
\begin{aligned}
& F\left(1^{\text {st }} \text { decision with reactive capacity }\right)-F\left(1^{\text {st }}\right. \text { decision without reactive capacity) } \\
& =\frac{c^{\prime}-c}{c^{\prime}+c_{e} e-s}-\frac{p-c-c_{e} e}{p-s}=\frac{(p-s)\left(c^{\prime}-c\right)-\left(p-c-c_{e} e\right)\left(c^{\prime}+c_{e} e-s\right)}{\left(c^{\prime}+c_{e} e-s\right)(p-s)} \\
& =\frac{(p-s)\left(c^{\prime}-c\right)-\left(p-s+s-c-c_{e} e\right)\left(c^{\prime}+c_{e} e-s\right)}{\left(c^{\prime}+c_{e} e-s\right)(p-s)} \\
& =\frac{(p-s)\left(c^{\prime}-c\right)-(p-s)\left(c^{\prime}+c_{e} e-s\right)+\left(c+c_{e} e-s\right)\left(c^{\prime}+c_{e} e-s\right)}{\left(c^{\prime}+c_{e} e-s\right)(p-s)} \\
& =\frac{(p-s)\left(c^{\prime}-c-c^{\prime}-c_{e} e+s\right)+\left(c+c_{e} e-s\right)\left(c^{\prime}+c_{e} e-s\right)}{\left(c^{\prime}+c_{e} e-s\right)(p-s)} \\
& =\frac{-(p-s)\left(c+c_{e} e-s\right)+\left(c+c_{e} e-s\right)\left(c^{\prime}+c_{e} e-s\right)}{\left(c^{\prime}+c_{e} e-s\right)(p-s)} \\
& =\frac{\left(c+c_{e} e-s\right)\left(-p+s+c^{\prime}+c_{e} e-s\right)}{\left(c^{\prime}+c_{e} e-s\right)(p-s)}=\frac{-\left(c+c_{e} e-s\right)\left(p-c^{\prime}-c_{e} e\right)}{\left(c^{\prime}+c_{e} e-s\right)(p-s)}<0,
\end{aligned}
$$

where the last equality holds since $p>c^{\prime}+c_{e} e$. So, we have

$$
F\left(1^{\text {st }} \text { decision with reactive capacity }\right)<F\left(1^{\text {st }} \text { decision without reactive capacity }\right)
$$

Since $F(\cdot)$ is a monotonically non-decreasing function, the production quantity without reactive capacity strategy tends to be larger than with reactive capacity strategy.

Q.E.D.

Since the firm with the reactive capacity production strategy has a second production chance after the demand is realized, it can have more profit-generating opportunity than the firm without the reactive capacity production strategy by grapping the demand which might be not satisfied by the initial production but can be satisfied by the second production even with the higher cost. This is explained in Lemma 5.

Lemma 5. The optimal expected profit with reactive capacity strategy is higher than the one without reactive capacity strategy. 
Proof. The expected profit without reactive capacity strategy is given by

$$
-c Q+c_{e}(A-e Q)+\int_{0}^{Q}\left(p D+s[Q-D]^{+}\right) f(D) d D+\int_{Q}^{\infty} p Q f(D) d D .
$$

and the expected profit with reactive capacity strategy is given by

$$
\begin{aligned}
-c Q+c_{e}(A-e Q) & +\int_{0}^{Q}\left(p D+s[Q-D]^{+}\right) f(D) d D+\int_{Q}^{\infty}\left(p D-\left(c^{\prime}+c_{e} e\right)[D-Q]^{+}\right) f(D) d D \\
= & -c Q+c_{e}(A-e Q)+\int_{0}^{Q}(p D+s[Q-D]) f(D) d D+\int_{Q}^{\infty} p Q f(D) d D \\
& +\int_{Q}^{\infty}\left(p[D(\omega)-Q]-\left(c^{\prime}+c_{e} e\right)[D-Q]\right) f(D) d D= \\
& =-c Q+c_{e}(A-e Q)+\int_{0}^{Q}(p D+s[Q-D]) f(D) d D+\int_{Q}^{\infty} p Q f(D) d D \\
& +\int_{Q}^{\infty}\left(p-c^{\prime}-c_{e} e\right)[D-Q] f(D) d D .
\end{aligned}
$$

The last term is always positive since $p>c^{\prime}+c_{e} e$ and $D-Q \geq 0$ due to $D \in[Q, \infty)$. So, for all $Q \geq$ 0 , we have

Moreover, we have

$$
\begin{aligned}
-c Q+c_{e}(A- & e Q)+\int_{0}^{Q}\left(p D+s[Q-D]^{+}\right) f(D) d D+\int_{Q}^{\infty} p Q f(D) d D \\
\leq & -c Q+c_{e}(A-e Q)+\int_{0}^{Q}\left(p D+s[Q-D]^{+}\right) f(D) d D \\
& +\int_{Q}^{\infty}\left(p D-\left(c^{\prime}+c_{e} e\right)[D-Q]^{+}\right) f(D) d D .
\end{aligned}
$$

$$
\begin{gathered}
\max _{Q \geq 0}-c Q+c_{e}(A-e Q)+\int_{0}^{Q}\left(p D+s[Q-D]^{+}\right) f(D) d D+\int_{Q}^{\infty} p Q f(D) d D \\
\leq \max _{Q \geq 0}-c Q+c_{e}(A-e Q)+\int_{0}^{Q}\left(p D+s[Q-D]^{+}\right) f(D) d D \\
+\int_{Q}^{\infty}\left(p D-\left(c^{\prime}+c_{e} e\right)[D-Q]^{+}\right) f(D) d D .
\end{gathered}
$$

Therefore, the optimal expected profit with reactive capacity strategy is larger than the one without reactive capacity strategy.

Q.E.D.

It is not clear that the amount of carbon permit traded under the carbon cap and trade system decreases or increases when the firm uses a reactive capacity production strategy. Its example will be provided in the following section of numerical example. However, at least we can generalize the expected amount of carbon permit traded under the carbon cap and trade system. More specifically, the analytical form for the expected amount of carbon permit traded under the carbon cap and trade system can be derived for the given demand distribution. These results can be seen in Proposition 2 and Corollary 1.

Proposition 2. Suppose that the firm uses a reactive capacity production strategy.

1. The firm's expected amount of carbon permit traded under the carbon cap and trade system is given by

$$
A-e Q^{W}-e E\left[D-Q^{W}\right]^{+}
$$


2. Suppose that the demand $D$ is normally distributed with mean $\mu$ and standard deviation $\sigma$. Then the firm's expected amount of carbon permit traded under the carbon cap and trade system is given by

$A-e F^{-1}\left(\frac{c^{\prime}-c}{c^{\prime}+c_{e} e-s}\right)-e \times \sigma$

$$
\times\left(\frac{1}{\sqrt{2 \pi}} e^{-\frac{\left(\frac{F^{-1}\left(\frac{c^{\prime}-c}{c^{\prime}+c_{e} e-s}\right)-\mu}{\sigma}\right)^{2}}{2}}-\left(\frac{F^{-1}\left(\frac{c^{\prime}-c}{c^{\prime}+c_{e} e-s}\right)-\mu}{\sigma}\right) \times \int_{\frac{F^{-1}\left(\frac{c^{\prime}-c}{c^{\prime}+c_{e} e-s}\right)-\mu}{\sigma}}^{\infty} \frac{1}{\sqrt{2 \pi}} e^{-\frac{x^{2}}{2}} d x\right)
$$

, where $F^{-1}\left(\frac{c^{\prime}-c}{c^{\prime}+c_{e} e-s}\right)$ is equal to $Q^{W}$ such that $\frac{c^{\prime}-c}{c^{\prime}+c_{e} e-s}=\int_{-\infty}^{\frac{Q^{W}-\mu}{\sigma}} \frac{1}{\sqrt{2 \pi}} e^{-\frac{x^{2}}{2}} d x$.

Proof.

With a reactive capacity production strategy, the first production quantity is given by $F^{-1}\left(\frac{c^{\prime}-c}{c^{\prime}+c_{e} e-s}\right)$ from Lemma 2 and let it be $Q^{W}$. Given the scenario $\omega$, we have carbon cap and trade constraint as follows,

$$
e Q^{W}+e\left[D-Q^{W}\right]^{+}+x=A
$$

where $x$ is the amount of carbon emission traded in the carbon trading market when the reactive capacity strategy is used. So, the expected amount of carbon emission traded in the carbon trading market is given by

$$
E[x]=E\left[A-e Q^{W}-e\left[D-Q^{W}\right]^{+}\right]=A-e Q^{W}-e E\left[\left[D-Q^{W}\right]^{+}\right] .
$$

Now, suppose that the demand $D$ is normally distributed. Then, the expected amount of carbon emission traded in the carbon trading market can be written as follows,

$$
\begin{aligned}
E[x]=E[A- & \left.e Q^{W}-e\left[D-Q^{W}\right]^{+}\right] A-e Q^{W}-e E\left[\left[D-Q^{W}\right]^{+}\right] \\
& =A-e Q^{W}-e \int_{Q^{W}}^{\infty}\left(D-Q^{W}\right) f(D) d D \\
& =A-e Q^{W}-e \times \sigma \times \int_{Q^{W}}^{\infty}\left(\frac{D-\mu}{\sigma}-\frac{Q^{W}-\mu}{\sigma}\right) f(D) d D \\
& =A-e Q^{W}-e \times \sigma \times \int_{z W}^{\infty}\left(x-z^{W}\right) g(x) d x \\
& =A-e Q^{W}-e \times \sigma \times\left(\int_{z^{W}}^{\infty} x \frac{1}{\sqrt{2 \pi}} e^{-\frac{x^{2}}{2}} d x-\int_{z^{W}}^{\infty} z^{W} \frac{1}{\sqrt{2 \pi}} e^{-\frac{x^{2}}{2}} d x\right) \\
& \left.=A-e Q^{W}-e \times \sigma \times\left(-\frac{1}{\sqrt{2 \pi}} e^{-\frac{x^{2}}{2}}\right]_{z^{W}}^{\infty}-z^{W} \int_{z^{W}}^{\infty} \frac{1}{\sqrt{2 \pi}} e^{-\frac{x^{2}}{2}} d x\right) \\
& =A-e Q^{W}-e \times \sigma \times\left(\frac{1}{\sqrt{2 \pi}} e^{-\frac{z^{W^{2}}}{2}}-z^{W} \int_{z^{W}}^{\infty} \frac{1}{\sqrt{2 \pi}} e^{-\frac{x^{2}}{2}} d x\right),
\end{aligned}
$$

where $f(D)=\frac{1}{\sigma \sqrt{2 \pi}} e^{-\frac{(D-\mu)^{2}}{2 \sigma^{2}}}, g(x)=\frac{1}{\sqrt{2 \pi}} e^{-\frac{x^{2}}{2}}, \mathrm{x}=\frac{D-\mu}{\sigma}$ and $z^{W}=\frac{Q^{W}-\mu}{\sigma}$. So, the result holds. 
Corollary 1. Suppose that the demand $D$ is normally distributed with mean $\mu$ and standard deviation $\sigma$ and the reactive capacity production strategy is used. Then, the expected total amount of carbon emitted by the firm when making the initial production decision is given by

$$
\begin{aligned}
& e F^{-1}\left(\frac{c^{\prime}-c}{c^{\prime}+c_{e} e-s}\right)+e \times \sigma \\
& \quad\left(\frac{1}{\sqrt{2 \pi}} e^{-\frac{\left(\frac{F^{-1}\left(\frac{c^{\prime}-c}{c^{\prime}+c_{e} e-s}\right)-\mu}{\sigma}\right)^{2}}{2}}-\left(\frac{F^{-1}\left(\frac{c^{\prime}-c}{c^{\prime}+c_{e} e-s}\right)-\mu}{\sigma}\right) \times \int_{F^{-1}\left(\frac{c^{\prime}-c}{c^{\prime}+c_{e} e-s}\right)-\mu}^{\infty} \frac{1}{\sigma} e^{-\frac{x^{2}}{2}} d x\right)
\end{aligned}
$$

where $F^{-1}\left(\frac{c^{\prime}-c}{c^{\prime}+c_{e} e-s}\right)$ is equal to $Q^{W}$ such that $\frac{c^{\prime}-c}{c^{\prime}+c_{e} e-s}=\int_{-\infty}^{\frac{Q^{W}-\mu}{\sigma}} \frac{1}{\sqrt{2 \pi}} e^{-\frac{x^{2}}{2}} d x$.

Proof.

After the demand is realized, total amount of carbon emission is given as follows,

$$
e Q^{W}+e\left[D-Q^{W}\right]^{+}
$$

when the reactive capacity strategy is used. So, the expected amount of carbon emission is as follows,

$$
E\left[e Q^{W}+e\left[D-Q^{W}\right]^{+}\right]=e Q^{W}+e E\left[\left[D-Q^{W}\right]^{+}\right]
$$

and using the second result of Proposition 2, this can be written as follows

$$
e Q^{W}+e E\left[\left[D-Q^{W}\right]^{+}\right]=e Q^{W}+e \times \sigma \times\left(\frac{1}{\sqrt{2 \pi}} e^{-\frac{z^{W^{2}}}{2}}-z^{W} \int_{z^{W}}^{\infty} \frac{1}{\sqrt{2 \pi}} e^{-\frac{x^{2}}{2}} d x\right)
$$

where $g(x)=\frac{1}{\sqrt{2 \pi}} e^{-\frac{x^{2}}{2}}, \mathrm{x}=\frac{D-\mu}{\sigma}$ and $z^{W}=\frac{Q^{W}-\mu}{\sigma}$. So, the result holds.

Q.E.D.

\section{Numerical Example}

In this section, we provide a numerical example to show the impact of a reactive capacity production under carbon cap and trade system on the firm's efficiency. The parameters for firm that we consider as an example are shown in Table 1 and the demand faced by the firm is normally distributed with mean $\mu$ and standard deviation $\sigma$.

\section{Table 1}

Parameters for a numerical example

\begin{tabular}{cccccccccc}
\hline Scenario & $p$ & $c$ & \multirow{2}{*}{$c^{\prime}$} & $s$ & $c_{e}$ & $e$ & $A$ & $\mu$ & $\sigma$ \\
\hline 1 & $\$ 180.0$ & $\$ 100.0$ & $\$ 120.0$ & $\$ 80.0$ & $\$ 10.0$ & 2 & 6,000 & 3,000 & 1,000 \\
2 & $\$ 200.0$ & $\$ 110.0$ & $\$ 130.0$ & $\$ 90.0$ & $\$ 10.0$ & 2 & 6,000 & 3,500 & 1,500 \\
3 & $\$ 260.0$ & $\$ 150.0$ & $\$ 180.0$ & $\$ 100.0$ & $\$ 10.0$ & 2 & 6,000 & 4,000 & 1,700 \\
\hline
\end{tabular}

As shown in Fig. 1, the production quantity without the reactive capacity production is larger than the one with the reactive capacity production. 


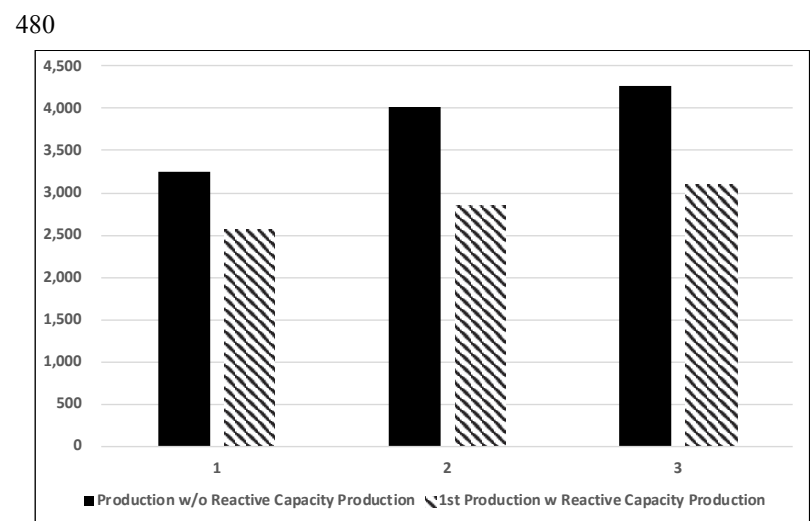

Fig. 1. $1^{\text {st }}$ Production Quantity with and without Reactive Capacity Production

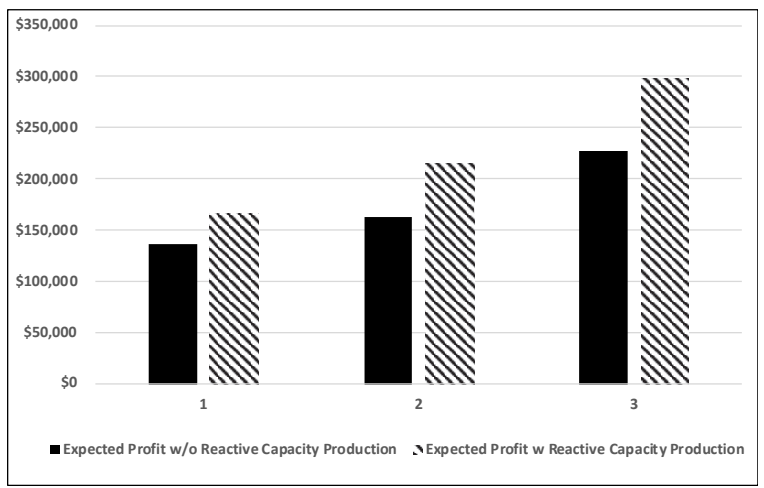

Fig. 2. Expected Profit with and without Reactive Capacity Production

The expected profit without the reactive capacity production is less than the one with the reactive capacity production even considering the carbon emission from the second production (Fig. 2). As mentioned in the previous section, the expected amount of carbon emission between with and without reactive capacity production is not clearly known as which one is larger. As shown in Fig. 3, the expected amount of carbon emission without the reactive capacity production for scenario 1 and 2 is higher than with the reactive capacity production. However, for scenario 3, the result is reversed. So, we cannot generalize which strategy generates more carbon emission.

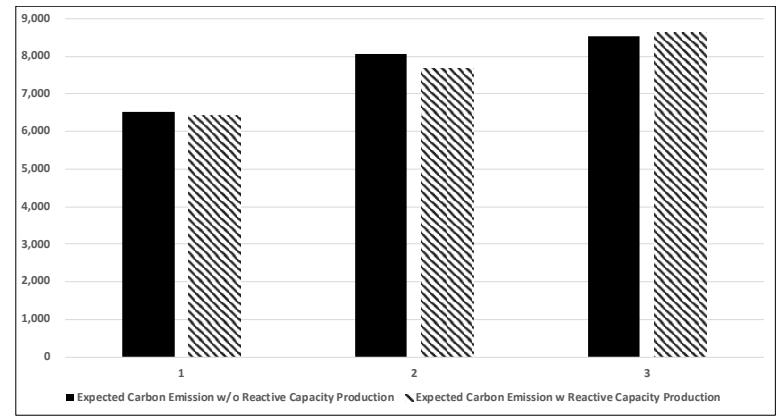

Fig. 3. Expected Carbon Emission with and without Reactive Capacity Production

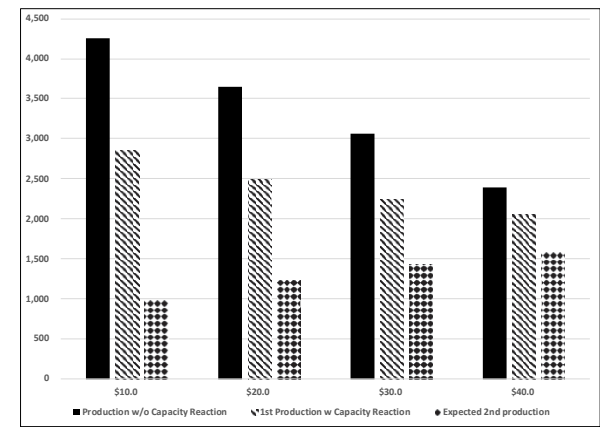

Fig. 4. Carbon price vs. Production Quantity

Now, using the four scenarios shown in Table 2, we will do a sensitivity analysis for carbon trading price $c_{e}$

Table 2

Parameters for change of carbon price $c_{e}$

\begin{tabular}{cccccccccc}
\hline Scenario & $p$ & $c$ & $c^{\prime}$ & $s$ & $c_{e}$ & $e$ & $A$ & $\mu$ & $\sigma$ \\
\hline 1 & $\$ 210.0$ & $\$ 100.0$ & $\$ 120.0$ & $\$ 80.0$ & $\mathbf{\$ 1 0 . 0}$ & 2 & 6,000 & 3,500 & 1,500 \\
2 & $\$ 210.0$ & $\$ 100.0$ & $\$ 120.0$ & $\$ 80.0$ & $\mathbf{\$ 2 0 . 0}$ & 2 & 6,000 & 3,500 & 1,500 \\
3 & $\$ 210.0$ & $\$ 100.0$ & $\$ 120.0$ & $\$ 80.0$ & $\mathbf{\$ 3 0 . 0}$ & 2 & 6,000 & 3,500 & 1,500 \\
4 & $\$ 210.0$ & $\$ 100.0$ & $\$ 120.0$ & $\$ 80.0$ & $\mathbf{\$ 4 0 . 0}$ & 2 & 6,000 & 3,500 & 1,500 \\
\hline
\end{tabular}

Fig. 4 shows that as the carbon trading price $c_{e}$ increases, the production quantity without the reactive capacity production and initial production quantity with the reactive capacity production decreases. Also, it shows that as the carbon trading price $c_{e}$ increases, the second expected production quantity with the reactive capacity production increases. These results are explained analytically in Lemma 2 and Lemma 4.

Now, using another four scenarios shown in Table 3, we will do a sensitivity analysis for the carbon emission per unit production $e$. 
Table 3

Parameters for change of Carbon emission per unit production $e$

\begin{tabular}{cccccccccc}
\hline Scenario & $p$ & $c$ & $c^{\prime}$ & $s$ & $c_{e}$ & $e$ & $A$ & $\mu$ & $\sigma$ \\
\hline 1 & $\$ 210.0$ & $\$ 100.0$ & $\$ 120.0$ & $\$ 80.0$ & $\$ 10.0$ & $\mathbf{2}$ & 6,000 & 4,000 & 1,700 \\
2 & $\$ 210.0$ & $\$ 100.0$ & $\$ 120.0$ & $\$ 80.0$ & $\$ 10.0$ & $\mathbf{3}$ & 6,000 & 4,000 & 1,700 \\
3 & $\$ 210.0$ & $\$ 100.0$ & $\$ 120.0$ & $\$ 80.0$ & $\$ 10.0$ & $\mathbf{4}$ & 6,000 & 4,000 & 1,700 \\
4 & $\$ 210.0$ & $\$ 100.0$ & $\$ 120.0$ & $\$ 80.0$ & $\$ 10.0$ & $\mathbf{5}$ & 6,000 & 4,000 & 1,700 \\
\hline
\end{tabular}

Fig. 5 shows that as the carbon emission per unit production $e$ increases, the production quantity without the reactive capacity production and initial production quantity with the reactive capacity production decreases. Also, it shows that as the carbon emission per unit production $e$ increases, the second expected production quantity with the reactive capacity production increases. These results are also explained analytically in Lemma 2 and Lemma 4.

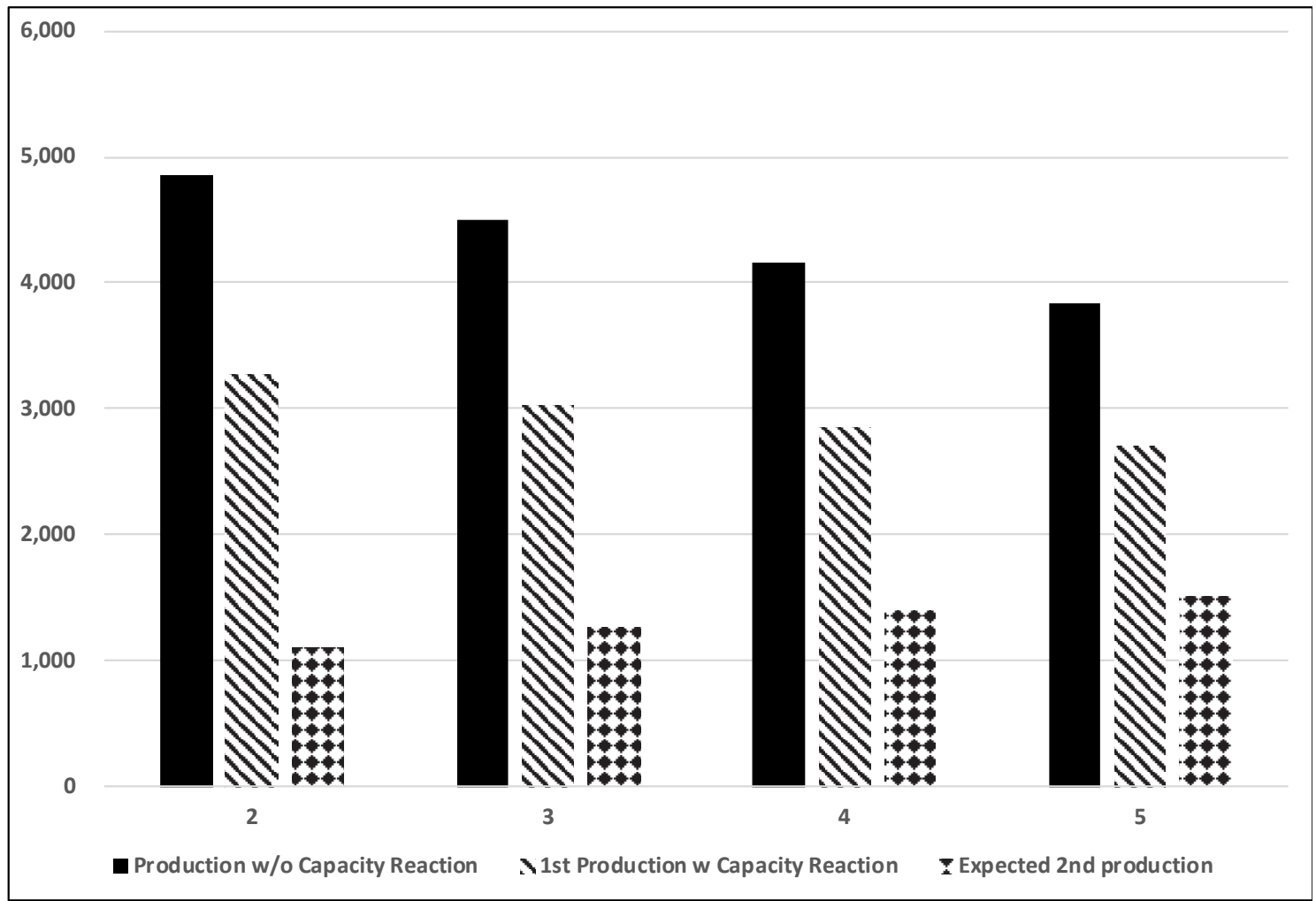

Fig. 5. Carbon emission per unit production vs. Production Quantity

\section{Conclusion}

In this study, we have considered the impact of a reactive capacity production system under the carbon cap and trade market on the firm's operational and financial efficiency. The firm has maintained two chances to choose the production quantities by considering total carbon emission from two production chances and carbon trading price in the carbon trading market. This is very practical but more complex than choosing a single chance for the production quantity since we need the carbon emission cap constraint including the carbon emission from both the first and also the second production which is not realized when deciding the first production.

We have shown that the firm with reactive capacity production under the carbon cap and trade system will choose the initial production quantity less than the firm without reactive capacity. Also we have shown that the firm with reactive capacity production under the carbon cap and trade system make more profit than the firm without reactive capacity even though its second production cost is higher 
than the initial production cost. We have also demonstrated that the firm's initial and second production decision with reactive capacity production strategy followed a monotone decreasing and nondecreasing property with respect to carbon price and the carbon emission per unit production, respectively. This would explain the firm's behavior by which the firm initially to make less production under the carbon cap and trade system but, if the demand is higher than the initial quantity of production, the firm would try to satisfy the rest of demand by second production even with higher production cost and carbon permit purchasing cost. The study was supported with a numerical example where it was not clear that the amount of carbon permit traded under the carbon cap and trade system could decrease or increase when the firm used a reactive capacity production strategy. Also, we have analytically provided the solution for the expected amount of carbon emission traded in the carbon trading market and the expected total amount of carbon emission by the firm with reactive capacity under the carbon cap and trade market.

The results we have shown in this study are very practical to use in many production industries facing the need to be environmentally responsible. In the future, the result can be extended to incorporate the dynamic pricing policy in the model which might be analytically hard to track.

\section{Acknowledgement}

This work was supported by 2018 Hongik University Research Fund.

\section{References}

An, J., \& Lee, J. (2018). A Newsvendor Non-Cooperative Game for Efficient Allocation of Carbon Emissions. Sustainability, 10(1), 154.

Cachon, G., \& Terwiesch, C. (2008). Matching supply with demand. McGraw-Hill Publishing.

Chen, X., Benjaafar, S., \& Elomri, A. (2013). The carbon-constrained EOQ. Operations Research Letters, 41(2), 172-179.

Caro, F., Corbett, C. J., Tan, T., \& Zuidwijk, R. (2013). Double counting in supply chain carbon footprinting. Manufacturing \& Service Operations Management, 15(4), 545-558.

Cachon, G. P. (2014). Retail store density and the cost of greenhouse gas emissions. Management Science, 60(8), 1907-1925.

Granot, D., Granot, F., \& Sosic, G. (2014). Allocation of greenhouse gas emissions in supply chains. University of Southern California Working Paper.

Du, S., Ma, F., Fu, Z., Zhu, L., \& Zhang, J. (2015). Game-theoretic analysis for an emission-dependent supply chain in a 'cap-and-trade'system. Annals of Operations Research, 228(1), 135-149.

Hovelaque, V., \& Bironneau, L. (2015). The carbon-constrained EOQ model with carbon emission dependent demand. International Journal of Production Economics, 164, 285-291.

Hua, G., Cheng, T. C. E., \& Wang, S. (2011). Managing carbon footprints in inventory management. International Journal of Production Economics, 132(2), 178-185.

Lee, J., Lee, M. L., \& Park, M. (2018). A Newsboy Model with Quick Response under Sustainable Carbon Cap-N-Trade. Sustainability, 10(5), 1410.

Letmathe, P., \& Balakrishnan, N. (2005). Environmental considerations on the optimal product mix. European Journal of Operational Research, 167(2), 398-412.

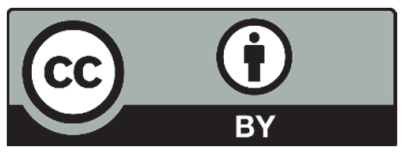

(C) 2019 by the authors; licensee Growing Science, Canada. This is an open access article distributed under the terms and conditions of the Creative Commons Attribution (CC-BY) license (http://creativecommons.org/licenses/by/4.0/). 